\title{
Recomendações para ensaio de resistência ao fogo em sistemas de paredes
}

\section{Recomendaciones Técnicas}

\section{Bernardo Tutikian}

Roberto Christ

Fabrício Bolina.

Luciane Caetano

Gustavo Prager

Eduardo Estevam

\section{Luiz Carlos Pinto da Silva Filho}

https://doi.org/10.21041/AlconpatInternacional/RecTec/2020-06-resistenciadeparedesalfuego

ALCONPAT Internacional

Asociación Latinoamericana de Control de Calidad, Patología y Recuperación de la Construcción

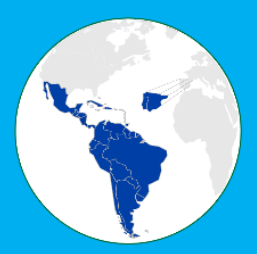




\section{ReCOMENDACIÓN TéCNICA}

\section{Editores}

Pedro Garcés Terradillos

Director de Recomendaciones Técnicas

Universidad de Alicante, España
Jorge Alberto Briceño Mena

Subdirector de Recomendaciones Técnicas

Cinvestav del IPN, Unidad Mérida, México
2020

Recomendações para ensaio de resistência ao fogo em sistemas de paredes

DOI: https://doi.org/10.21041/AlconpatInternacional/RecTec/2020-06resistenciadeparedesalfuego

Recomendaciones para probar la resistencia al fuego en sistemas de pared

\section{Recommendations for testing fire resistance in wall systems}

\section{Bernardo Tutikian}

Universidad de Vale do Rio dos Sinos (UNISINOS), São Leopoldo, Brazil.

\section{Roberto Christ}

Universidad de Vale do Rio dos Sinos (UNISINOS), São Leopoldo, Brazil.

\section{Fabrício Bolina}

Universidad de Vale do Rio dos Sinos (UNISINOS), São Leopoldo, Brazil.

\section{Luciane Caetano}

Federal University of Rio Grande do Sul (UFRGS), Porto Alegre, Brazil.

\section{Gustavo Prager}

Universidad de Vale do Rio dos Sinos (UNISINOS), São Leopoldo, Brazil.

\section{Eduardo Estevam}

Universidad de Vale do Rio dos Sinos (UNISINOS),

São Leopoldo, Brazil.

\section{Luiz Carlos Pinto da Silva Filho}

Federal University of Rio Grande do Sul (UFRGS), Porto Alegre, Brazil. 


\section{Recomendación Técnica No. 6}

\section{ENSAIO DE RESISTÊNCIA AO FOGO EM SISTEMAS DE PAREDES}

\section{OBJETIVO}

Esta Recomendação Técnica tem como objetivo definir a sequência de análise laboratorial em ensaios de resistência ao fogo em paredes com e sem função estrutural, bem como estabelecer as diretrizes para interpretação dos fenômenos observados durante estas análises, além de propor uma classificação final destes sistemas segundo os resultados obtidos.

\section{INTRODUÇÃO}

A segurança contra incêndio das edificações é um requisito necessário para preservar a vida dos usuários durante o evento de um incêndio. A necessidade de atestar os sistemas construtivos em termos de resistência ao fogo se torna uma poderosa ferramenta para assegurar a integridade da edificação em chamas por um determinado período de tempo, suficiente para oportunizar a evacuação dos usuários, garantir o trabalho das equipes de resgate e proteger as edificações vizinhas, preservando vidas e patrimônio.

No entanto, o conceito de resistência ao fogo aplicável aos sistemas construtivos pode ser analisado sobre duas perspectivas. A primeira, sobre o ponto de vista de compartimentação, requer que o fogo não seja propagado para os cômodos contíguos, bem como não proporcione a passagem de gases quentes e o incremento de temperatura ao ambiente adjacente, evitando a proliferação do incêndio. A segunda, sobre o ponto de vista estrutural, requer que um determinado elemento, durante o evento de um incêndio, além de cumprir com os requisitos de compartimentação, não venha a colapsar e comprometer o equilíbrio do sistema estrutural da edificação (quando lhe for admitido uma reponsabilidade estrutural).

Para assegurar a compartimentação de um sistema de paredes não estruturais (de vedação), o mesmo deve satisfazer os requisitos de estabilidade, estanqueidade e isolamento térmico. Para assegurar a integridade de um sistema de paredes estruturais (autoportantes) o mesmo deve satisfazer, além dos requisitos de compartimentação, de resistência mecânica.

\section{TERMOS E DEFINIÇÕES}

Os termos e definições apresentados na sequência serão admitidos no decorrer desta recomendação técnica.

\subsection{Amostra}

Sistema característico e representativo empregado para a realização do ensaio, executado de forma idêntica ao que será produzido em obra. 


\subsection{Desempenho ao fogo}

Comportamento da parede quando submetida ao fogo.

\subsection{Elemento}

Parte de um sistema de parede com funções específicas.

\subsection{Falha}

Circunstância que prejudica ou compromete o desempenho ao fogo do sistema.

\subsection{Resistência ao fogo}

Capacidade da parede de resistir aos requisitos mínimos desta norma quando submetida ao fogo

\subsection{Ruína}

Situação que caracteriza o Estado-Limite último do sistema

\subsection{Sistema}

Conjunto de elementos que compõe a parede

\section{REQUISITOS DE RESISTÊNCIA AO FOGO}

Para efeito de ensaio de resistência ao fogo de sistemas paredes internas e externas, os conceitos fundamentais apresentados devem ser admitidos. O sistema deve ser acoplado no forno na posição vertical e, uma vez iniciado o ensaio, os requisitos apresentados a seguir devem ser analisados e continuamente monitorados.

\subsection{Estabilidade}

Característica fundamental de um sistema de parede com ou sem função estrutural de manter-se íntegro durante o evento de um incêndio, não colapsando ou apresentando deformações térmicas excessivas.

\subsection{Estanqueidade}

Característica fundamental de um sistema de parede com ou sem função estrutural de evitar a passagem direta - através de fissuras - de gases quentes entre um ambiente em chamas e o ambiente contíguo a este. 


\subsection{Isolamento térmico}

Característica fundamental de parede com ou sem função estrutural reter o calor no ambiente em que há o desenvolvimento da combustão, preservando o cômodo contíguo do aumento de temperatura.

\subsection{Resistência mecânica}

Característica fundamental de um sistema de parede com função estrutural não apesentar ruína prematura ou deformações térmicas excessivas a ponto de comprometer o equilíbrio global de um sistema estrutural ou os estados limites do elemento.

\section{APARELHAGEM}

Os equipamentos necessários para a realização dos ensaios de resistência ao fogo estão descritos na sequência.

\subsection{Pórtico móvel}

Equipamento no qual o sistema a ser ensaiado será montado. Ele deve ser composto por um quadro rígido e constituído por perfis metálicos, oferecendo a possibilidade de engastar a parede (amostra a ser ensaiada) em todo o seu perímetro. O pórtico móvel deve ser concebido com um dispositivo que permita a sua acoplagem junto ao forno vertical em que se realizará o ensaio.

\subsection{Forno de ensaio}

Deverá seguir as imposições estabelecidas. $\mathrm{O}$ forno deverá submeter à parede ao fogo em uma das faces.

\subsubsection{Dispositivo de acoplagem}

$\mathrm{O}$ forno vertical deve conter um dispositivo que permita a acoplagem do pórtico móvel (no qual o sistema a ser ensaiado será montado). Sistemas de macho e fêmea com engate ou ligação parafusada são alternativas para cumprir com este propósito.

\subsubsection{Janela de inspeção interna}

O forno vertical deve conter uma janela de inspeção, selada com vidro resistente a chamas, para que se realize um acompanhamento contínuo do comportamento da face interna da amostra (exposta ao fogo).

\subsubsection{Temperatura do forno}

O forno vertical deve ter a capacidade de submeter a amostra a uma evolução padronizada de temperatura. A evolução de temperatura deve respeitar a seguinte equação:

$$
\mathrm{T}-\mathrm{T}_{\mathrm{o}}=345 \cdot \log (8 \mathrm{t}+1)
$$

Sendo:

$\mathrm{t}=$ tempo de ensaio;

$\mathrm{T}_{\mathrm{o}}=$ temperatura natural do ambiente no início do ensaio;

$\mathrm{T}=$ temperatura interna do forno.

A curva representativa desta expressão, chamada de "curva da evolução padronizada de temperatura", é apresentada na Figura 1. 


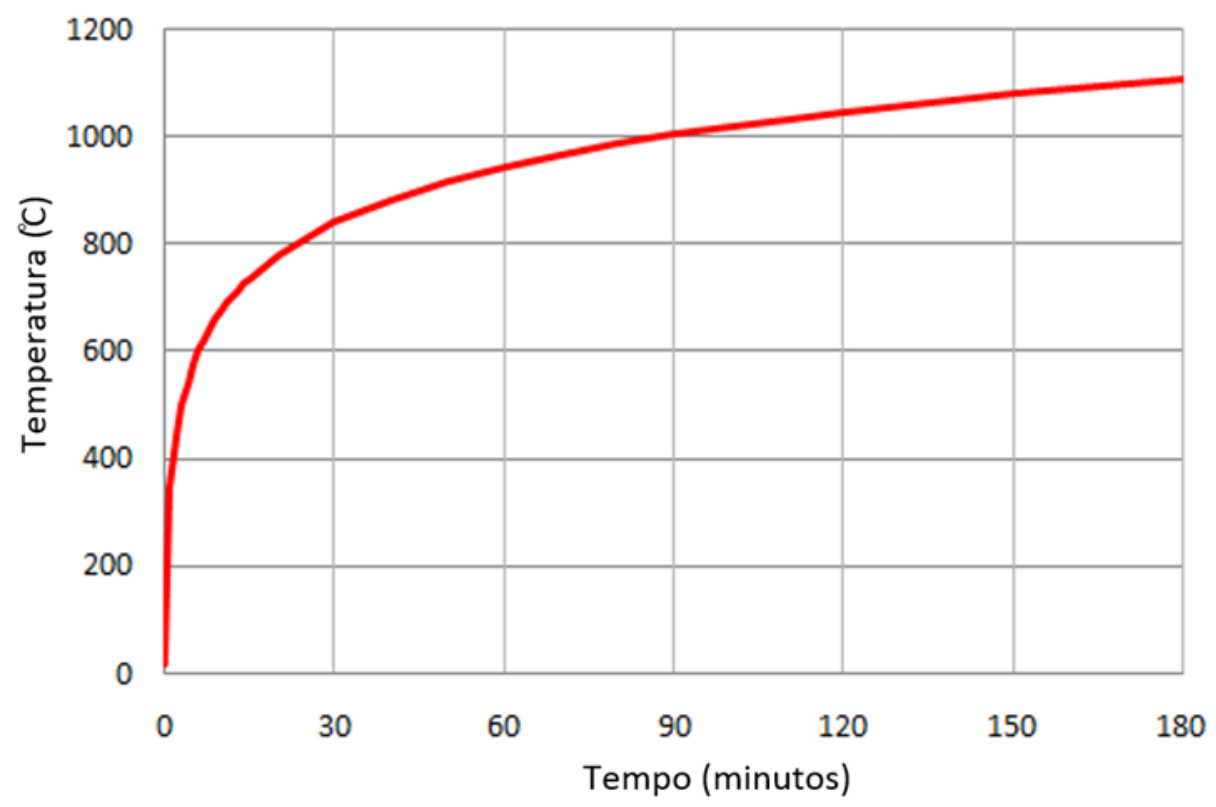

Figura 1. Curva da evolução padronizada de temperatura

Os desvios máximos de temperatura são:

$\pm 15 \%$ nos primeiros 10 minutos de ensaio;

$\pm 10 \%$ nos subsequentes 20 minutos de ensaio;

$\pm 5 \%$ após os 30 minutos de ensaio.

Caso o forno não obedeça a estes limites, o ensaio deve ser interrompido e invalidado.

\subsubsection{Materiais de construção do forno}

O forno deve submeter à amostra a elevação padronizada de temperatura supracitada. O forno não pode proporcionar perda de estanqueidade, devendo ser projetado para tanto. Deve ser revestido internamente com tijolos refratários de baixa densidade (cerca de $50 \mathrm{lbs} / \mathrm{ft} 3(775 \mathrm{~kg} /$ $\mathrm{m} 3)$ ), comprovadamente resistente a temperaturas de, no mínimo, $1425^{\circ} \mathrm{C}$. Sobre os tijolos deve ser aplicado um revestimento com um material de fibra cerâmica, com espessura mínima de $30 \mathrm{~cm}$.

\subsubsection{Combustível}

Os fornos devem ter como elemento combustível o gás liquefeito de petróleo (GLP).

\subsubsection{Queimadores}

Os queimadores de gás devem ser com prémistura. Estes queimadores controlam minuciosamente a quantidade do combustível fornecido e do ar de combustão injetado, produzindo uma chama uniforme. Os queimadores pré-misturados produzem altas velocidades da chama do gás dentro do forno.

\subsubsection{Capacidade de ar secundário}

O forno deve conter um sistema capaz de fornecer ar secundário quando a quantidade de oxigénio em seu interior estiver inferior a $6 \%$. Um caminho de fluxo de ar secundário dentro do forno pode ser necessário para manter este nível de oxigénio, em especial nos casos em que a amostra ensaiada for combustível. Amostras de gás devem ser recolhidas continuamente, através de um tubo de amostragem, onde a determinação do oxigénio deve ser realizada utilizando um analisador de oxigênio paramagnético tipo A.

\subsubsection{Controle de pressão diferencial}

Deve ser previsto um meio para controlar a pressão interna do forno. 


\subsubsection{Profundidade mínima do forno}

A profundidade do forno influencia o aumento da temperatura por radiação. A profundidade do forno vertical para este tipo de ensaio de resistência ao fogo deverá ser de, no mínimo, 1,2 metros.

\subsubsection{Pressão diferencial}

A pressão interna deve ser registrada - no mínimo - em um ponto. Os sensores que determinam a pressão interna devem estar localizados no interior do forno, sujeito ao fluxo direto das correntes de convecção de chamas ou na trajetória dos gases quentes gerados pelos queimadores. A média das pressões registradas durante todo o ensaio deve estar compreendida entre $10 \pm 5 \mathrm{~Pa}$. A forma de determinação da pressão interna do forno deve obedecer às prescrições da ISO 834 e EN1363.

\subsection{Termopares}

\subsubsection{Termopares da amostra}

Todos os termopares empregados para a medição das temperaturas devem ser do tipo "K", apresentando uma variação máxima de precisão de $\pm 2^{\circ} \mathrm{C}$. Todos os termopares devem ser constantemente calibrados por laboratórios creditados. O intervalo de calibração de cada termopar não pode exceder $40 \mathrm{~h}$ de ensaio. Os termopares novos só poderão ser utilizados após a sua devida calibração. É dever do responsável pelos ensaios guardar os atestados de calibração de cada termopar.

Cada termopar utilizado para a medição da temperatura da face não exposta ao fogo da amostra deve ser colado em um disco de cobre de $12 \mathrm{~mm}$ de diâmetro e $0,2 \mathrm{~mm}$ de espessura. Os discos devem ser recobertos com pastilhas de amianto de $30 \mathrm{~mm} \quad x \quad 30 \mathrm{~mm} \quad x \quad 2 \mathrm{~mm}$ (comprimento, largura e espessura), com densidade aproximada de $1000 \mathrm{~kg} / \mathrm{m} 3$. As pastilhas de papelão de amianto devem ser fixadas na superfície da amostra por meio de pinos, fitas ou adesivos adequados, dependendo do material que compõe a face não exposta.

\subsubsection{Termopares do forno}

Todos os termopares do forno devem ser isolados, incorporando os termopares em cabos com bainha de metal e isolamento mineral. Todos os termopares devem ser constantemente calibrados por laboratórios acreditados. O intervalo de calibração de cada termopar não pode exceder $40 \mathrm{~h}$ de ensaio. Os termopares novos só poderão ser utilizados após a sua devida calibração. É dever do responsável pelos ensaios guardar os atestados de calibração de cada termopar.

\subsection{Estufa de secagem}

A estufa deve possuir um controle da temperatura interna, devendo garantir a convecção natural de ar. A temperatura interna da estufa deve ser de $100^{\circ} \mathrm{C}$. Deve possuir porta com abertura, permitindo a fácil colocação e retirada dos materiais no interior da câmara, e porta com sistema magnético para oferecer um bom fechamento, com perfil de silicone.

\subsection{Câmera térmica}

A câmera térmica deve ser do tipo fixa, instalada com o auxílio de um tripé ou de uma bancada devidamente estável, posicionada a uma distância ideal na qual se consiga capturar toda a área superficial da amostra. 


\subsection{Trena digital}

Deve possuir precisão milimétrica e ser posicionada para que se obtenha a distância de modo perpendicular a face da amostra. A trena deve ser instalada em nível.

\subsection{Haste metálica}

Retrátil, com comprimento mínimo de $2,5 \mathrm{~m}$ e, em um de seus extremos, bastidor quadrado de $100 \mathrm{~mm}$ de lado, devendo o chumaço de algodão ser fixado com grampo de aço.

\subsection{Cronômetro}

Preferencialmente digital, para uma maior precisão.

\section{PREPARO DA AMOSTRA}

\subsection{Montagem do sistema}

O sistema deve possuir dimensões mínimas de $2,5 \times 2,5 \mathrm{~m}$ e, obrigatoriamente, ser confeccionado com materiais de mesmas características com as que serão empregados na construção. As espessuras e disposição de juntas, revestimentos e vinculação da amostra devem ser idênticas a utilizada in loco. Caso seja empregado no sistema algum tipo de mistura (argamassa, concreto, etc.), a proporção entre os materiais constituintes deve ser fiel ao praticado em obra.

A amostra deve ser montada sobre um pórtico móvel que permita, sem oferecer qualquer tipo de dano, uma acoplagem perfeita junto ao forno vertical de ensaio.

As condições e período de cura, quando aplicável, devem ser respeitadas. Para os sistemas que exigirem esta condição, deverá ser anotada diariamente (durante todo o período admitido para a cura do sistema) a umidade relativa do ar, excetuando-se os finais de semana (sábado e domingo). As medições devem ser realizadas às $10 \mathrm{hs}$ da manhã e às $15 \mathrm{hs}$ da tarde, preferencialmente.

\subsection{Instalação dos termopares internos do forno (fixos)}

O número mínimo de termopares internos do forno deve ser 5. Um destes termopares deve estar posicionado no alinhamento do baricentro da amostra. Cada termopar deve ter uma área de influência igual a $1,5 \mathrm{~m}^{2}$.

\subsection{Instalação dos termopares das amostras (não fixos)}

O número mínimo de termopares a serem instalados na face externa da amostra (não expostas diretamente ao fogo) deve ser 5 . Um destes termopares deve estar posicionado exatamente no baricentro da superfície da amostra. Cada termopar deve ter uma área de influência igual a $1,5 \mathrm{~m}^{2}$. 


\subsection{Preparo do chumaço de algodão}

O chumaço de algodão a ser empregado nas análises de estanqueidade das paredes deve ser devidamente seco em estufa a uma temperatura de $100^{\circ} \mathrm{C}$ durante, pelo menos, 30 minutos. O chumaço de algodão deve ser retirado do forno instantes antes do início do ensaio. $\mathrm{O}$ chumaço de algodão, em circunstância alguma, poderá ser reutilizado.

\section{ACOMPANHAMENTO DO ENSAIO}

\subsection{Paredes sem função estrutural}

Deve-se observar as condições de estabilidade, estanqueidade e isolamento térmico do sistema.

\subsubsection{Estabilidade}

O sistema deve ter um acompanhamento contínuo de sua deformação ao longo do ensaio. Uma trena a laser, posicionada a uma distância compreendida entre $3 \mathrm{~m}$ e $4 \mathrm{~m}$ da superfície externa da amostra não submetida a chamas deve medir a deformação no baricentro da parede. Esta leitura deve ser realizada em intervalos de, no máximo, 5 minutos. Quebras pontuais e um eventual colapso deve ser observado.

Para paredes sem função estrutural, a estanqueidade deve também ser observada após o teste de choque mecânico, descrito em 9.1.4.

\subsubsection{Estanqueidade}

Deve-se realizar uma análise contínua sobre microfissuras ou fissuras que se formem sobre o sistema. Esta análise deve ser realizada: (a) de forma visual e (b) com o auxílio de uma câmera térmica. Em cada fissura deflagrada, um chumaço de algodão (novo, seção quadrada de lados $100 \mathrm{~mm}$ e espessura 20mm) deve ser aproximado a uma distância compreendida entre $20 \mathrm{~mm}$ e $30 \mathrm{~mm}$ da superfície desta, durante um intervalo de tempo compreendido entre $10 \mathrm{~s}$ e 20s. Não ocorrendo a inflamação do chumaço de algodão, o processo deve ser repetido a cada 10 minutos, devendo - obrigatoriamente - realizarse uma medição no intervalo de tempo de classificação da amostra (15min, 30min, $45 \mathrm{~min}$, 60min, $90 \mathrm{~min}, 120 \mathrm{~min}, 180 \mathrm{~min}, 240 \mathrm{~min}$ e 360 $\min )$.

\subsubsection{Isolamento térmico}

O isolamento térmico é observado continuamente, através do acompanhamento da temperatura dos termopares instalados na face externa da amostra (não submetida a chamas).

\subsection{Paredes com função estrutural}

Durante o ensaio dos sistemas de vedação vertical com função estrutural deve-se observar as condições de estabilidade, estanqueidade, isolamento térmico e resistência mecânica do sistema.

\subsubsection{Estabilidade}

O sistema deve ter um acompanhamento contínuo de sua deformação ao longo do ensaio. Uma trena a laser, posicionada a uma distância compreendida entre $3 \mathrm{~m}$ e $4 \mathrm{~m}$ da superfície externa da amostra não submetida a chamas deve medir a deformação no baricentro da parede. 
Esta leitura deve ser realizada em intervalos de, no máximo, 5 minutos. Quebras pontuais e um eventual colapso deve ser observado.

\subsubsection{Estanqueidade}

Deve-se realizar uma análise contínua sobre microfissuras e fissuras que se formem sobre o sistema. Esta análise deve ser realizada: (a) de forma visual e (b) com o auxílio de uma câmera térmica. Em cada fissura deflagrada, um chumaço de algodão (novo, seção quadrada de lados $100 \mathrm{~mm}$ e espessura 20mm) deve ser aproximado a uma distância compreendida entre $20 \mathrm{~mm}$ e $30 \mathrm{~mm}$ da superfície desta, durante um intervalo de tempo compreendido entre $10 \mathrm{~s}$ e 20s. Não ocorrendo a inflamação do chumaço de algodão, o processo deve ser repetido a cada 10 minutos.

\subsubsection{Isolamento térmico}

O isolamento térmico é observado continuamente, através do acompanhamento da temperatura dos termopares instalados na face externa da amostra (não submetida a chamas).

\subsubsection{Resistência mecânica}

Com a aplicação do carregamento necessário para submeter o elemento a um estado de tensão, um acompanhamento da deformação (conforme critério estabelecido em 8.2.1), além de fissuras estruturais ou eventual ruína, deve ser realizado na análise.

\section{CONDUÇÃO DO ENSAIO}

\subsection{Sistema de parede sem função estrutural}

Deve-se proceder com as ações apresentadas na sequência.

\subsubsection{Anotações dos fenômenos evidenciados}

Deve-se ter um acompanhamento contínuo do sistema durante o ensaio. Todos os fenômenos observados (início da propagação da fissura, descolamentos, desplacamentos, etc.) devem ser registrados. Deve ser anotado o tipo do fenômeno constatado e o instante do ensaio em que o mesmo fora identificado. Outro laboratorista deve analisar concomitantemente os fenômenos na face interna da amostra, através da janela de inspeção do forno.

\subsubsection{Deformações da amostra}

Deve ser medido (perpendicularmente a face da amostra) o deslocamento da amostra continuamente durante o ensaio, em pelo menos um ponto, com auxílio de equipamento de medição (trena digital) com precisão de $1 \mathrm{~mm}$. O deslocamento deve ser medido no ponto mais crítico da amostra, ou seja, no seu baricentro. $\mathrm{O}$ deslocamento do sistema de parede deve ser realizado em intervalos máximos de 5 minutos. Este acompanhamento deve ser realizado segundo 6.1.1.

\subsubsection{Teste do chumaço de algodão}

Deve-se ter uma preocupação especial quando for observada uma fissura. Se a mesma começar a expelir gases quentes dentre a sua abertura, um chumaço de algodão deve ser aproximado desta, e realizada a sequência apresentada em 6.1.2.

\subsubsection{Teste de choque mecânico}

Submeter a superfície não exposta ao fogo da amostra a um impacto de uma esfera de aço segundo um movimento pendular, com massa de $25 \mathrm{~kg}$. Os impactos devem ser realizados em um mesmo alinhamento horizontal da superfície externa (não exposta às chamas) da parede, preferencialmente a uma distância de $1,4 \mathrm{~m}$ da base da amostra. Este ensaio deve ser realizado 3 minutos antes de um dos tempos normativo de classificação $(15,30,45,60,90,120,150,180$, 240 e 360 minutos, o que for aplicável). É dispensado o teste de choque mecânico nas paredes classificadas como CF15, PC15, CF30 e PC30. Na aplicação do impacto, caso a parede não perca nenhum de seus requisitos de resistência ao fogo, o ensaio prossegue. 


\subsection{Sistema de parede com função estrutural}

Além do contínuo acompanhamento dos requisitos de resistência ao fogo apresentado no item 5 (anotações dos fenômenos evidenciados, deformações da amostra e teste do choque mecânico), deve-se proceder com as ações apresentadas na sequência.

\subsubsection{Aplicação de carga}

Em sistemas construtivos com função estrutural é necessário que a amostra seja submetida a um carregamento. $\mathrm{O}$ conjunto de aplicação de carga deve ser realizado mediante um sistema de aplicação de força automática, com regulagem de velocidade de aplicação de cargas em uma taxa de carregamento definida. O sistema deverá ser composto por, no mínimo, três cilindros hidráulicos dispostos simetricamente por todo comprimento da amostra. A carga aplicada deve ser determinada através de uma célula de carga, sendo registrada durante todo o ensaio.

A aplicação da carga na amostra deverá ser realizada antes do início do ensaio, sendo necessário esperar a estabilização (acomodação) das tensões. O esforço aplicado deve ser de mesma grandeza que especificado em projeto, devendo ser mantido constante durante todo o ensaio. Caso haja uma variação na carga aplicada, esta deverá ser reestabelecida em, no máximo, 10 segundos.

\subsubsection{Deformações da amostra}

Além das deformações descritas em 7.1.2, para os sistemas com função estrutural deve-se também registrar as deformações axiais, no sentido de aplicação da carga, com auxílio de equipamento com precisão de $1 \mathrm{~mm}$, observando os princípios dispostos em 6.2.1.

\subsubsection{Teste do chumaço de algodão}

Deve-se ter uma preocupação especial quando for observada uma fissura. Se a mesma começar a expelir gases quentes dentre a sua abertura, um chumaço de algodão deve ser aproximado desta, e realizada a sequência apresentada em 6.2.2.

\section{INTERPRETAÇÃO DOS RESULTADOS}

\subsection{Paredes sem função estrutural}

Os requisitos aplicados para avaliação do sistema de paredes (sem função estrutural) submetido a chamas são descritos na sequência.

\subsubsection{Estabilidade}

Será considerada estável toda a amostra que não colapsar ou apresentar deformações acima dos limites estabelecidos (durante todo o ensaio).

\subsubsection{Estanqueidade}

Será considerada estanque toda a amostra que, ao fissurar, não provocar a inflamação do chumaço de algodão que lhe for aproximado ou chamejamento com duração inferior a 10s.

\subsubsection{Isolamento térmico}

Admite-se que a amostra possui isolamento térmico quando a temperatura de um termopar não superar $180^{\circ} \mathrm{C}$ e a média aritmética de todos os termopares não superar $140^{\circ} \mathrm{C}$, descontado a temperatura do início do ensaio. 


\subsection{Paredes com função estrutural}

Os requisitos aplicados para avaliação do sistema de paredes (com função estrutural) submetido a chamas são descritos na sequência.

\subsubsection{Estabilidade}

Será considerada estável toda a amostra que não colapsar ou apresentar deformações acima dos limites estabelecidos (durante todo o ensaio). A deformação aceitável deverá ser aquela o projetista estrutural (da edificação em que a parede será inserida) informar para que sejam atendidos os estados limites de serviço da estrutura. A combinação das ações para determinar estes estados limites admissíveis do sistema analisado deverá ser elaborada através dos modelos de cálculo corriqueiramente admitidos pelas normas de projeto, excetuandose as ações do vento.

\subsubsection{Estanqueidade}

Será considerada estanque toda a amostra que, ao fissurar, não provocar a inflamação do chumaço de algodão que lhe for aproximado ou chamejamento com duração inferior a 10s.

\subsubsection{Isolamento térmico}

Admite-se que a amostra possui isolamento térmico quando a temperatura de um termopar não superar $180^{\circ} \mathrm{C}$ e a média de todos os termopares não superar $140^{\circ} \mathrm{C}$, descontado a temperatura do início do ensaio.

\subsubsection{Resistência mecânica}

Uma amostra terá competência estrutural (resistência mecânica) quando for capaz de manter a sua integridade (estabilidade, estanqueidade e isolamento térmico) sob o estado de tensão que lhe for submetida (carregamento).

\section{CLASSIFICAÇÃO FINAL DA AMOSTRA}

\subsection{Paredes sem função estrutural}

O período admitido para a classificação da $\mathrm{O}$ período admitido para a classificação da amostra deve ser aquele contabilizado desde o início do ensaio até o instante em que houver a perda de algum dos requisitos definidos para análise da amostra (tempo de ensaio). A classificação final do sistema deve respeitar um dos tempos padronizados de ensaio.

Segundo o período de tempo em que a amostra cumpre com os requisitos de análise, as amostras sem função estrutural podem ser caracterizadas como corta-fogo ou para-chamas e, então, enquadradas em uma classe de resistência ao fogo.
As amostras corta-fogo são aquelas que cumpriram os requisitos de (a) estabilidade, (b) estanqueidade e (c) isolamento térmico, podendo ser classificadas como CF15V, CF30V, CF45V, CF90V, CF120V, CF180V, CF240V, CF360V.

As amostras para-chamas são aquelas que cumpriram os requisitos de (a) estabilidade e (b) estanqueidade, podendo ser classificadas como PC15V, PC30V, PC45V, PC90V, PC120V, PC180V, PC1240V, PC1360V 


\subsection{Paredes com função estrutural}

O tempo de resistência ao fogo da parede com função estrutural será $80 \%$ do tempo durante o qual o elemento esteve carregado e cumprindo com os requisitos de resistência ao fogo.

As amostras corta-fogo são aquelas que cumpriram os requisitos de (a) estabilidade, (b) estanqueidade e (c) isolamento térmico, podendo ser classificadas como CF15E, CF30E, CF45E, CF90E, CF120E, CF180E, CF240E, CF360E.
As amostras para-chamas são aquelas que cumpriram os requisitos de (a) estabilidade e (b) estanqueidade, podendo ser classificadas como PC15E, PC30E, PC45E, PC90E, PC120E, PC180E, PC1240E, PC1360E.

\section{CLASSIFICAÇÃO FINAL DA AMOSTRA}

O relatório de ensaio deve apresentar, no mínimo, as seguintes informações:

a. Nome e endereço do laboratório de ensaio, do proponente e a data da realização do ensaio;

b. Os detalhes de construção da amostra de ensaio, incluindo a descrição dos principais componentes e desenhos técnicos. Caso o desenho e detalhamento não forem entregues pelo cliente, este deverá ser feito pelo laboratório e anexado ao relatório de ensaio;

c. As características geométricas da amostra (largura, altura e espessura);

d. As características físicas de cada elemento constitutivo da amostra;

e. As propriedades dos componentes que têm uma influência sobre o desempenho do produto quando exposto às chamas, tais como juntas de dilatação, espessuras e traço das camadas de assentamento, espessura e traço do revestimento, etc.;

f. método de montagem e instalação do corpo de prova junto ao forno;

g. Para elementos com função estrutural, especificar a carga total aplicada durante todo o período de ensaio; h. Informar a localização de todos os termopares dispostos na amostra;

i. A temperatura ambiente do laboratório durante o início do teste;

j. A pressão interna do forno durante todo o ensaio;

k. A curva de temperatura/tempo atingida internamente do forno;

1. tempo total de ensaio;

m. Registros de todos os fatos ocorridos ao longo do tempo, tais como deflexão máxima, temperatura máxima atingida, formação de fissuras, abertura da fissura, entre outros. Os registros devem ser expressos em minutos, entre o início do aquecimento e o tempo em ocorreu o fato;

n. Os registros da câmera térmica no instante em que se identificar alguma fissura ou aumento repentino de temperatura, devendo obrigatoriamente e quando aplicável ser efetuado um registro em cada período de tempo de classificação da amostra (15min, 30min, $45 \mathrm{~min}, 60 \mathrm{~min}, 90 \mathrm{~min}$, $120 \mathrm{~min}, 180 \mathrm{~min}, 240 \mathrm{~min}$ e $360 \mathrm{~min}$ );

o. A classificação final da amostra. 


\section{BIBLIOGRAFÍA}

Os documentos descritos a seguir são auxiliares para a aplicação deste documento, devendo este prevalecer sobre os demais. Na ausência de qualquer informação constante neste material, os documentos abaixo podem ser consultados.

1. AMERICAN SOCIETY FOR TESTING AND MATERIALS. ASTM E 119: Standard Test Methods for Fire Tests of Building Construction and Materials.

2. AMERICAN SOCIETY FOR TESTING AND MATERIALS. ASTM E 605: Standard Test Methods for Thickness and Density of Sprayed Fire Resistive Material Applied to Structural Members.

3. AMERICAN SOCIETY FOR TESTING AND MATERIALS. ASTM E 736: Standard Test Method for Cohesion/Adhesion of Sprayed Fire Resistive Materials Applied to Structural Members

4. ASSOCIAÇÃO BRASILEIRA DE NORMAS TÉCNICAS. ABNT NBR 5628: Componentes construtivos estruturais - Determinação da resistência ao fogo.

5. ASSOCIAÇÃO BRASILEIRA DE NORMAS TÉCNICAS. ABNT NBR 10636: Paredes divisórias sem função estrutural - Determinação da resistência ao fogo.

6. BRITISH STANDARDS INSTITUTION. BS 476-1: Fire Tests on Building Materials and Structures.

7. DEUTSCHE NORM. DIN 4102: Fire behavior, building materials and elements. Part 1: classification of building materials, requeriments and testing.

8. EUROPEAN COMMITTEE FOR STANDARDIZATION. Eurocode 2: Design of concrete structures - Part 1-2: General rules - Structural fire desing.

9. INTERNATIONAL ORGANIZATION FOR STANDARDIZATION. ISO 834-1: Fireresistance tests - Elements of building construction - Part 1: General requirements.

10. INDIAN STANDARD. IS 1642: Fire safety of buildings: details of construction - code of practice.

11. JAPANESE STANDARDS ASSOCIATION. JIS A 1304: Method of fire resistance test for strucutral parts of buildings.

12. NATIONAL INSTITUTE OF STANDARDS AND TECHNOLOGY. Fire Resistance Testing for Performance-based Fire Design of Buildings.

13. STANDARDS ASSOCIATION OF AUSTRALIA. Methods for fire tests on building materials, components and structures. Part 4: Fire-resistance test of elements of construction.

14. UNDERWRITERS LABORATORIES OF CANADA. CAN/ULC S101: Standard Methods of Fire Endurance Tests of Building Construction and Materials. 